\title{
THE USE OF HYBRID VEHICLES AS A PROPOSAL FOR REDUCING CO2 EMISSIONS AND ITS CONTRIBUTION TO REDUCING GREENHOUSE GAS EMISSIONS
}

\author{
C. A. R. de Carvalho, \\ and W. Q. Lamas \\ University of Taubate \\ Postgraduate Programme in Mechanical \\ Engineering \\ Rua Daniel Danelli, s/n - Jd. Morumbi \\ 12060-440, Taubate, SP, Brazil \\ carlosalfredo.carvalho@hotmail.com,
}

wendell@unitau.br

\section{ABSTRACT}

The problems related to energy consumption and pollutant emissions for the transport sector represent a major global concern regarding climate changes caused by greenhouse gases, directly related to the increased level of gas emissions from fossil fuels, the main one being carbon dioxide. One way to minimize this problem is through the introduction of new technologies. Hybrid cars are one of the new technology options that has the main advantage of reducing fuel consumption and therefore reducing the amount of $\mathrm{CO}_{2}$ in the atmosphere. This paper gives an introduction to hybrid vehicles, with the aim of presenting their main advantages and evaluate their impact on emissions of $\mathrm{CO}_{2}$ in the Brazilian fleet, compared to conventional vehicles.

Keywords: $\mathrm{CO}_{2}$ emissions, fuel consumption, hybrid vehicles.

\section{NOMENCLATURE}

AR average round by a vehicle, $\mathrm{km} / \mathrm{year}$

ER emission rate of $\mathrm{CO}_{2}$ per vehicle, $\mathrm{t} /$ year

$\mathrm{PEF}$ pollutant emission factor, $\mathrm{g} / \mathrm{km}$

$\mathrm{N}$ number of vehicles in the year

\section{INTRODUCTION}

Climate change and the increase in greenhouse gases are the main topics of discussion today in global discussions. The discussion of global warming covers possible causes and consequences, who are responsible for warming and what steps should be taken by countries to reduce the negative impacts of this phenomenon.

The burning of fossil fuels around the world is the main cause of emissions of carbon dioxide $\left(\mathrm{CO}_{2}\right)$, the main greenhouse gas. The transport sector is among the sources of emissions of greenhouse gases, the fastest-growing, often at a rate higher than the GNP (Gross National Product) of developing countries (Schipper and Marie-Lilliu, 1999; Wills, 2008).

The conventional vehicles using internal combustion engines, and energy generated by these engines is the result of burning a mixture of fuel and air. This burning, it is not a complete chemical reaction and generates at the end of the cycle, exhaust gases that are expelled into the atmosphere. The emission of gases from vehicles is composed of: carbon monoxide $(\mathrm{CO})$, nitrogen oxide $\left(\mathrm{NO}_{\mathrm{x}}\right)$, hydrocarbons $(\mathrm{HC})$, sulphur oxides $\left(\mathrm{SO}_{\mathrm{x}}\right)$ and soot, also known as particulate matter. Although $\mathrm{CO}_{2}$ is not considered a classic pollutant due to its low toxicity and even to be a result of any burning, should be taken into account in order to participate in the "greenhouse effect".

Fossil fuels used by motor vehicles, as well as contributing to higher levels of air pollution, are not renewable energy source. In this scenario, the automotive industry has invested in technologies to improve fuel economy, reduced emissions while maintaining performance levels, security, reliability, and maintenance of the other attributes applied to vehicles in use today.

In Brazil, aiming to reduce the problems related to emissions of pollutants from motor vehicles, the National Council for the Environment (CONAMA) in 1986, launched the Control of Air Pollution by Motor Vehicles (PROCONVE), based on programs already in place in developed countries, such as the European standard EURO. The program has established a schedule for gradual reduction of pollutant emissions for light vehicles (cars) and heavy vehicles (buses and trucks). Therefore, it set emission limits for $\mathrm{CO}, \mathrm{NO}_{\mathrm{x}}$, and $\mathrm{HC}$, also automakers should adopt technological measures (improvement in fuel injection, catalysts, recycling of gases etc.). In order to meet the limits, otherwise it will have to sell vehicles that do not meet these limits prohibited domestically.

The PROCONVE not impose limits on emissions of $\mathrm{CO}_{2}$, as a result of any gas burning, but its contents are directly related to the rate of fuel consumption. In an attempt to reduce fuel consumption and therefore greenhouse gas emissions, the federal government launched in April 2009 the Brazilian Program of Efficiency and Labeling Vehicle (PEB vehicular), which allows 
consumers to compare the use of vehicles with different fuels, stimulating both the production and use of vehicles more efficient and cleaner.

In this scenario, the demand for greater fuel economy, reduced emissions without sacrificing vehicle performance, safety and reliability have been doing with the automakers develop new technologies, in order to meet new market demands. This study is an approach to the use of hybrid technology as a proposal to increase energy efficiency and consequently the rate of emissions.

\section{EXPERIMENTS}

This paper aims as proposal to present, as a first stage, a simplified method for calculating $\mathrm{CO}_{2}$ emissions from burning gasoline and alcohol fuel, and an estimate of emissions of pollutants into the national fleet of cars and SUVs sold, based on data from emissions of carbon monoxide, and amount of light vehicles and SUVs sold.

The second stage aims at presenting the operation mode of hybrid technology and improvements in fuel consumption and also emission levels of carbon dioxide with its use.

In conclusion, it would make a comparison between the estimated volume of $\mathrm{CO}_{2}$ emissions from the fleet of light vehicles and SUVs sold in Brazil from 2005 to 2009 and which this volume would be considering the scenario of integration of the hybrid vehicle from 2005 .

\section{THEORY}

\section{Combustion Stoichiometry}

Considering that gasoline used in Brazil (type C) has $22 \%$ of anhydrous ethanol in it (E22) and the use of flex-fuel vehicles, that percentage ranges from $22 \%$ ("pure" gasoline) to $100 \%$ ethanol (E100). From there it can calculate the emission of $\mathrm{CO} 2$ for the extreme cases E22 and E100.

For burning E22 gasoline, considering the density of gasoline $\mathrm{Dg}=0.740 \mathrm{~kg} / \mathrm{L}$ and of ethanol $\mathrm{De}=0.791 \mathrm{~kg} / \mathrm{L}$, the burning of 1 litre, it has Eq. (1).

$$
0.78 \times 0.740+0.22 \times 0.791=0.577 \mathrm{kgC}_{8} \mathrm{H}_{18}+0.174 \mathrm{kgC}_{2} \mathrm{H}_{6} \mathrm{O}
$$

For pure gasoline, it has the following list of masses (in grams) in the burning of one litre, Eq. (2).

$$
\begin{aligned}
& \mathrm{C}_{8} \mathrm{H}_{18}+12.5 \mathrm{O}_{2} \rightarrow 8 \mathrm{CO}_{2}+9 \mathrm{H}_{2} \mathrm{O} \\
& (8 \times 12+18 \times 1)+(12.5 \times 16 \times 2) \rightarrow 8 \times(12+16 \times 2)+9 \times(2 \times 1+16) \\
& 114 \mathrm{gC}_{8} \mathrm{H}_{18}+400 \mathrm{O}_{2} \rightarrow 352 \mathrm{gCO}_{2}+162 \mathrm{gH}_{2} \mathrm{O}
\end{aligned}
$$

Result: 0.577 kilograms of gasoline corresponds to 1.766 kilograms of $\mathrm{CO}_{2}$ (fossil portion)

To anhydrous ethanol, it has the following list of masses (in grams) in the burning of one litre, Eq. (3).

$$
\begin{aligned}
& \mathrm{C}_{2} \mathrm{H}_{6} \mathrm{O}+3 \mathrm{O}_{2} \rightarrow 2 \mathrm{CO}_{2}+3 \mathrm{H}_{2} \mathrm{O} \\
& (12 \times 2+1 \times 6+16)+3 \times(16 \times 2) \rightarrow 2 \times(12+16 \times 2)+3 \times(2 \times 1+16) \\
& 46 \mathrm{gC}_{2} \mathrm{H}_{6} \mathrm{O}+96 \mathrm{O}_{2} \rightarrow 88 \mathrm{gCO}_{2}+54 \mathrm{gH}_{2} \mathrm{O}
\end{aligned}
$$

Result: 0.174 kilograms of anhydrous ethanol corresponds to 0.332 kilograms of $\mathrm{CO}_{2}$ (renewable portion)

Then the total mass of $\mathrm{CO}_{2}$ emitted from burning one litre of E22 gasoline is 2.098 kilograms and the burning of one litre of alcohol E100 is 1.513 kilograms.

It is important to remember that the above calculations are considering a complete burning, which in practice does not exist. For the actual burning should be considered in addition to the $\mathrm{O}_{2}$, Nitrogen, which also is a component of air, then there will be emission of pollutants.

Full burning: Fuel $+\mathrm{Air} \rightarrow \mathrm{CO}_{2}+\mathrm{H}_{2} \mathrm{O}$

Actual burning: Fuel $+\mathrm{O}_{2}+\mathrm{N}_{2} \rightarrow \mathrm{CO}_{2}+\mathrm{H}_{2} \mathrm{O}$ $\underbrace{+\mathrm{CO}+\mathrm{NO}_{\mathrm{x}}+\mathrm{CHO}+\mathrm{HC}}_{\text {POLLUTANTS }}$

But as emissions levels of these other results from burning are controlled by PROCONVE and are relatively low compared to emissions levels of carbon dioxide, which cannot take into account these figures, given only to the calculations the value of CO emission (ANFAVEA, 2009).

Figure 1 shows an evolution of the PL standard for gases in question.

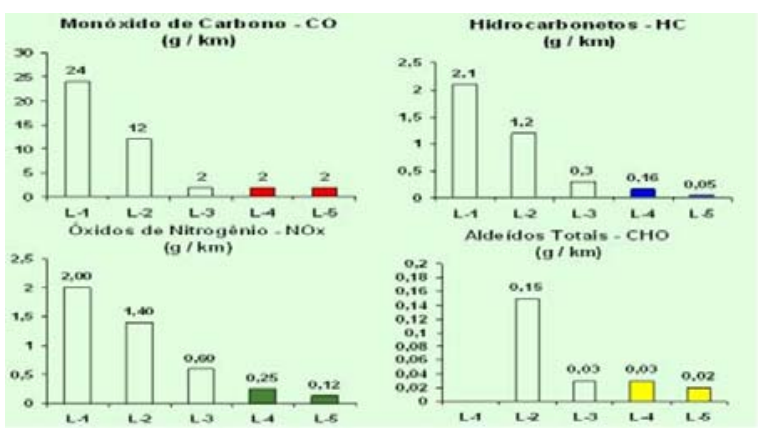

Figure 1. Evolution of emission limits.

\section{Methodology for Estimating of $\mathrm{CO}_{2}$ Emissions}

This estimate is based on methods for making inventories of vehicular emissions (Murgel et al., 1987; Landmann, 2004; Teixeira et al., 2008; Alvares Junior and Linke, 2001). To calculate the estimate of emissions was used the Eq. (4).

$$
\mathrm{ER}=\mathrm{PEF} \times \mathrm{AR} \times 10^{-6} \times \mathrm{N}
$$

To achieve the emission calculations, the first step is to raise the amount of $\mathrm{gCO}_{2} / \mathrm{km}$ emitted per vehicle (PEF), which can be obtained by multiplying the values $\mathrm{gCO}_{2} / \mathrm{L}$ (calculation described in Eqs. (1)- 
(3)) and average fuel consumption $\mathrm{km} / \mathrm{L}$, however, for this work will be used average actual emissions. The next step is to determine the average mileage driven per vehicle, and finally raise the amount of vehicles. In this case, will be restricted to light vehicles and SUVs sold from 2005 until the first half of 2009.

\section{The Hybrid Vehicle (Queiroz, 2006)}

Any vehicle that combines two or more sources of energy that can provide propulsion power, directly or indirectly, is a hybrid. They are usually vehicles that use an internal combustion engine and an electric motor as an alternative source of energy. For this study will be considered a hybrid vehicle, a light vehicle with an electric motor and an internal combustion engine powered by gasoline.

Hybrid vehicles run on an internal combustion engine, but are also able to convert energy into electricity that is stored in a battery until the electric motor is in operation, pulling the vehicle, thus saving the energy required by the internal combustion engine. This allows the internal combustion engine is more efficient, use less fuel and thus produces fewer pollutants. Therefore, the electric motor is used when the internal combustion engine efficiency is low, i.e. when accelerating when going up a hill, when at low speed, pulled or when the car stops. In breaking the gasoline engine automatically shuts down and the electric is turned on, and through regenerative braking the battery can be recharged. Thus, the electric motor kicks in when it is to save fuel. Unlike electric vehicles, hybrid vehicles do not need to be connected to external sources of electricity, using only energy from the combustion engine and regenerative brakes.

The combination of two sources of energy is more efficient than the internal combustion engine or electric motor alone. Hybrid vehicles can be configured in several ways, combining the internal combustion engine is better with the electric motor assist, improving fuel economy and reducing pollution without sacrificing ride quality and performance.

\section{Hybrid systems}

As already described in this section, hybrid systems use a combination of internal combustion engines and electric motors, and are made in its basic structure by a gasoline engine, fuel tank, electric motor, generator, batteries, and transmission. A brief characterization of each one follows.

The hybrid car has a gasoline engine very similar to that found in most cars. However, the engine of a hybrid is smaller and uses advanced technologies to reduce emissions and increase efficiency.
The fuel tank in a hybrid vehicle is the storage device to power the gasoline engine. Gasoline has an energy density much higher than that of batteries. For example, it needs 450 grams of batteries to store the same energy generated by 3.79 litres or 3 kilograms of gasoline.

Electric motor in a hybrid car is very sophisticated machinery. The advanced electronic technology to its role as both a motor and as a generator. For example, if it needs this kind of car can draw power from the batteries to accelerate. However, acting as a generator, it can stop the vehicle and return energy to the batteries.

Generator is similar to an electric motor, but acts only to produce electricity. It is mainly used in hybrid as series arrangement.

The batteries of a hybrid car are the storage device to power the electric motor. Unlike gasoline in the fuel tank, which can trigger only the gasoline engine, the electric motor in a hybrid car can provide power for the batteries and still draw energy from them.

Transmission in a hybrid car performs the same basic function that the transmission in a conventional car. Some hybrids, like the Honda Insight, have conventional transmissions. Others, like the Toyota Prius, have very different transmission, which uses a system of division of power, consisting of planetary gears.

Is possible to combine the two sources of energy found in a hybrid car in different ways. The configurations of hybrid vehicles can be three different types: series system, parallel system, and combined system.

In the series system configuration the internal combustion engine is used as a generator providing power to the electric motor and battery. The internal combustion engine is not mechanically coupled to the wheels, and may be controlled, thus generating efficiency optimisation control of reaching emission levels, regardless of their driving conditions. In this case, the gasoline engine does not move directly from the vehicle, only the electric motor drive the wheels.

In the parallel system configuration the internal combustion engine is mechanically coupled to the wheels being able to supply the required power. The electric motor is mounted parallel to the internal combustion engine so that it can add the torque required for its operation. The internal combustion engine can then drive the electric motor as a generator, thus charging the battery. This system does not require a generator as the series system. Both the gasoline engine and electric motor can turn the transmission at the same time and the transmission then turns the wheels.

In the case of series-parallel combined system this one uses the characteristics of systems in series and parallel together; requires both functions, a generator and a motor. The mechanical power of the 
internal combustion engine is divided by a planetary gear set in the package (the internal combustion engine to the generator) and the package in parallel (the internal combustion engine to the wheels). The Toyota Prius is an example of this application, also known as the dual or mixed.

\section{Performance of hybrid vehicles}

In a hybrid vehicle the gasoline engine can be much smaller than that of a conventional car and therefore is more efficient. Most cars need a relatively big engine to produce enough power for rapid acceleration of the vehicle. In a small engine, however, the efficiency can be improved by use of parts smaller and lighter by reducing the number of cylinders and the engine operating closer to its maximum load.

Below are some reasons for the efficiency of smaller engines compared to larger one:

- The larger engine is heavier, so that the car uses extra energy when accelerating or must face an incline;

- The pistons and other internal components are heavier, requiring more energy always up and down the cylinder;

- The displacement of the cylinders is greater, so that more fuel is required for each cylinder;

- Larger engines usually have more cylinders, each of which uses fuel when the engine is turned on, even if the car is not moving.

This explains why two cars of the same model but with different engines, may have different fuel consumption. If the two cars travelling on a highway at the same speed, one that has smaller engine uses less energy. Both engines need to produce the same level of power to propel the car, but the smaller engine uses less energy. The hybrid car uses a smaller engine, and when there is a need for increased efforts, the hybrid vehicle uses the electric motor.

Besides the engine smaller and more efficient, hybrids currently use many other features to reduce fuel consumption (aerodynamics, lighter materials, occasional shutdown of combustion engines etc.). Some can be applied to any type of car and others apply only to a hybrid, with the goal of maximizing fuel.

Hybrid cars on the market use some or all of these resources to improve their efficiency. The bestselling hybrid vehicle market is the Toyota Prius, according to surveys and even Toyota, has the average consumption of $25 \mathrm{~km} / \mathrm{L}$ of fuel. The data for this vehicle will be taken as a basis for studies of this article.

\section{RESULTS AND DISCUSSION}

Based on the methodology for the calculation, was raised the amount of commercial vehicles and light trucks sold in the Brazilian market from 2005 to 2009, as showed in Fig. 2.

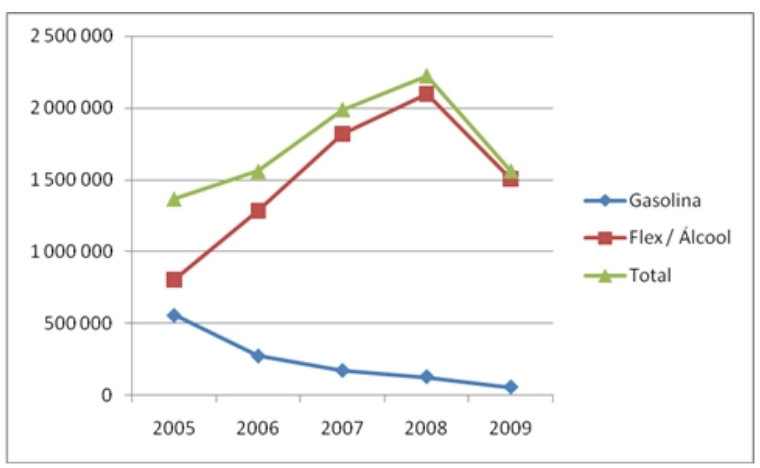

Figure 2. Amount of light vehicles sold from 2005 to 2009.

To estimate the mileage values were used for average annual mileage of the fleet of cars, estimated by CETESB to their inventories for gasoline and alcohol vehicles. With such numbers, is obtained Tab. 1 .

Table 1. General rate of annual mileage.

\begin{tabular}{|l|c|}
\hline Vehicle type & km/year \\
\hline Gasoline & 12,000 \\
\hline Alcohol / Flex & 18,300 \\
\hline Diesel & 80,000 \\
\hline Motorcycles and similar & 12,000 \\
\hline
\end{tabular}

The PEF, pollutant emissions factor, was considered the average emissions $(\mathrm{g} / \mathrm{km})$ in 2006 to $170 \mathrm{gCO}_{2} / \mathrm{km}$ (Wills, 2008). Based on these values, it can estimate the emission of carbon dioxide ( $\mathrm{t} / \mathrm{year}$ ) for vehicles sold in this period (Fig. 3).

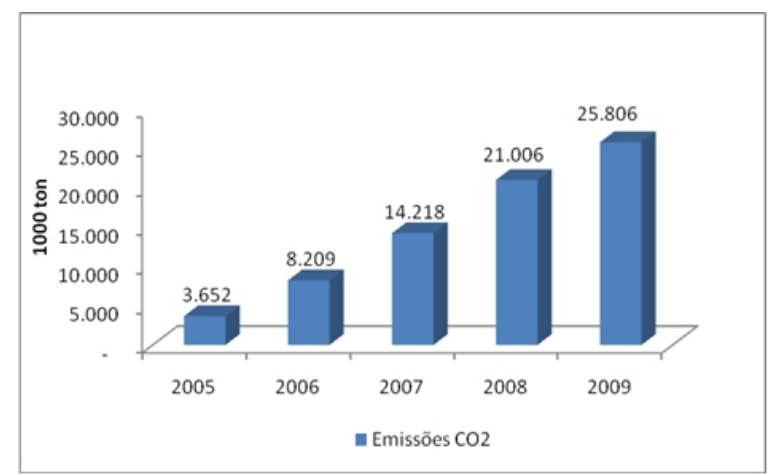

Figure 3. $\mathrm{CO}_{2}$ emissions for conventional vehicles from 2005 to 2009.

For the same period, the calculation was done considering the inclusion of hybrid vehicle 
technology in the domestic market in three different scenarios. The first scenario is the current, with $0 \%$ inclusion of hybrid vehicles, the second scenario assumes that $50 \%$ of flex-alcohol cars sold being hybrid vehicles and the third scenario assumes $100 \%$ of the flex-alcohol cars sold being hybrid vehicles. The average annual mileage was considered the same as alcohol vehicles $(18,300 \mathrm{~km} / \mathrm{year})$, and PEF, was based on the Toyota Prius, $104 \mathrm{gCO}_{2} / \mathrm{km}$ (Mancini, 2009).

Figure 4 presents a comparison of estimates of annual $\mathrm{CO}_{2}$ emissions for each proposed scenario.

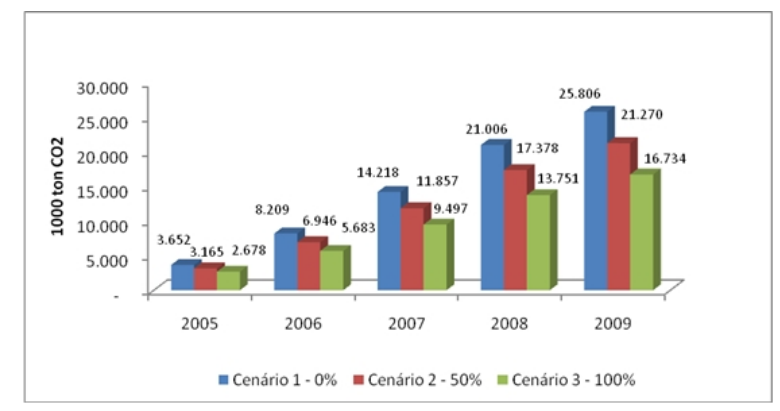

Figure 4. Comparison of $\mathrm{CO}_{2}$ emission for current fleet vs. hybrid fleet.

From the data it appears that by $200550 \%$ of the fleet of flex-alcohol sold in the country were of hybrid vehicles, in 2009 the amount of $\mathrm{CO}_{2}$ emitted would be about $18 \%$ lower, and the entire volume of flex-alcohol sold were of hybrid vehicles, the amount of tons of carbon dioxide emitted in 2009 would be $35 \%$ lower.

Recalling that the study is restricted to the amount of this vehicles type, not considering the other vehicles of the national fleet.

\section{CONCLUSIONS}

The use of new technologies in the automotive industry has become a necessity, and more than that, a trend with regard to efforts to reduce the volume of pollutants emitted by vehicles. Even due to the fact that the laws governing this sector to be increasingly accurate.

According to the results, it appears that hybrid technology has a significant role in efforts to reduce the gases causing the greenhouse effect, especially $\mathrm{CO}_{2}$, which is closely linked to fuel consumption, with the main purpose of the hybrid car is to have greater energy efficiency.

In Brazil, hybrid technology is not widespread, the first steps are being taken with the production of hybrid buses and motorcycles. The great difficulty in signing this technology is due to the added cost and lack of incentives by the government. Importantly, this technology not only brings environmental benefits, but also economic, because of its low consumption.
With the launch of the labelling program and the reduction of vehicular pollution limits, the hybrid technology should become the object of focus to meet the new demands of the market in coming years.

\section{REFERENCES}

Alvares Junior, O. M., and Linke, R. R. A., 2001, Simplified methodology for calculating emissions of greenhouse gas vehicle fleet in Brazil, CETESB.

http://homologa.ambiente.sp.gov.br/proclima/PDF/in ventario_efeitoestufa.pdf (Accessed Aug 2009). (in Portuguese)

Landmann, M. C., 2004, Estimated emissions of pollutants from cars in the RMSP considering the traffic routes, in: II Meeting of the National Association of Postgraduate Studies and Research in Environment and Society (ANPPAS), ANPPAS, Indaiatuba, $\quad \mathrm{SP}, \quad 11 \quad$ p. http://www.anppas.org.br/encontro_anual/encontro2/ GT/GT11/marcelo_camilli.pdf (Accessed Aug 2009). (in Portuguese)

Mancini, E., 2009, Hybrid vehicles, in: Fuels Seminar, The Brazilian Association of Automotive Engineering (AEA), Sao Paulo. (in Portuguese)

Murgel, E. M., Szwarc, A., and Santos, M. D. S. R., 1987, Vehicular emissions inventory: methodology for calculating, CETESB. (in Portuguese)

National Association of Automobile Manufacturers (ANFAVEA), 2009, Sales wholesale market by type of fuel, ANFAVEA. http://www.anfavea.com.br/tabelas/autoveiculos/tabe la11_vendas.pdf (Accessed Aug 2009). (in Portuguese)

Queiroz, J. F., 2006, Introduction of the Hybrid Vehicle in Brazil: Technological Developments Coupled with the Quality of Life, Master Thesis, University of Sao Paulo, Sao Paulo, Brazil. (in Portuguese)

Schipper, L., and Marie-Lilliu, C., 1999, Transportation and $\mathrm{CO}_{2}$ emissions: flexing the linka path for the World Bank, The World Bank Environment Department and the Transport, Water and Urban Unit. (Climate Change Series).

Teixeira, E. C., Feltes, S., and Santana, E. R. R., 2008, Study of the Emissions from Moving Sources in the Metropolitan Area of Porto Alegre - RS Brazil, Quimica Nova, Vol. 31, No. 2, pp. 244-248. (in Portuguese)

Wills, W., 2008, The Increase of Energy Efficiency in Light Vehicles and Its Consequences to the Greenhouse Gases Emissions - Brazilian Scenarios Between 2000 and 2030, Master Thesis, Federal University of Rio de Janeiro, Rio de Janeiro, Brazil. (in Portuguese) 